\title{
miRNA-124 in Immune System and Immune Disorders
}

\author{
Zhen Qin ${ }^{\dagger}$, Peng-Yuan Wang ${ }^{\dagger}$, Ding-Feng Su* and Xia Liu* \\ Department of Pharmacology, School of Pharmacy, Second Military Medical University, Shanghai, China
}

In recent years, miR-124 has emerged as a critical modulator of immunity and inflammation. Here, we summarize studies on the function and mechanism of miR-124 in the immune system and immunity-related diseases. They indicated that miR-124 exerts a crucial role in the development of immune system, regulation of immune responses, and inflammatory disorders. It is evident that miR-124 may serve as an informative diagnostic biomarker and therapeutic target in the future.

OPEN ACCESS

Edited by:

Fulvio D'Acquisto,

Queen Mary University

of London, UK

Reviewed by:

Albrecht Pliper,

Universitätsklinikum Frankfurt,

Germany

Paula Barbim Donate

Universidade de São Paulo, Brazil

${ }^{*}$ Correspondence:

Xia Liu

Ixflying@aliyun.com;

Ding-Feng Su

dfsu@smmu.edu.cn

tZhen Qin and Peng-Yuan Wang contributed equally to this work.

Specialty section:

This article was submitted to Inflammation,

a section of the journal

Frontiers in Immunology

Received: 31 July 2016 Accepted: 21 September 2016

Published: 04 October 2016

Citation:

Qin Z, Wang P-Y, SU D-F and Liu X (2016) miRNA-124 in Immune

System and Immune Disorders.

Front. Immunol. 7:406.

doi: 10.3389/fimmu.2016.00406
Keywords: miRNA-124, biomarker, target, immunity, immune disorders

\section{INTRODUCTION}

microRNAs (miRNAs) are a class of short non-coding single-stranded molecules with 18-25 nt, involved in the post-transcriptional regulation of gene expression $(1,2)$. miRNA biogenesis is initiated via transcription by RNA polymerase II as part of capped and polyadenylated primary transcripts (pri-miRNAs) (2). The pri-miRNAs are further processed by a complex called "Microprocessor," consisting of a member of the ribonuclease III family (Drosha) and its cofactor (DGCR8), to release an approximately 65-nt stem-loop precursor miRNA (pre-miRNA). The resulting pre-miRNAs are exported by exportin- 5 to the cytoplasm where hairpin precursor sequences are cleaved by the Dicer enzyme to generate 22-bp double-stranded miRNA duplexes. Mature miRNA in the duplexes is released by helicase and assembled into RNA-induced silencing complex (RISC) to recognize and silence the target (3-6).

miRNAs are increasingly being distinguished as crucial modulators of gene expression in many biological processes, such as cell maturation (7), differentiation, proliferation (8), metastasis (9), apoptosis (2), and autophagy (10). Specifically, miR-124 was initially verified by cloning studies in mice (11). There are three subtypes of miR-124, named miR-124-1, miR-124-2, and miR-124-3, which have distinct chromosome locations. While the precursors of miR-124 from different species are different, the sequences of mature miR-124 in human, mice, rats are completely identical. Noteworthily, miR-124 is the most abundantly expressed miRNA in neuronal cells and is highly expressed in the immune cells and organs, including peripheral blood mononuclear cells, bone marrow, lymph node, and thymus (Figure 1) (11-13).

miR-124 in the RISC recognizes target mRNAs through imperfect base pairing. Its seed region, approximately 7-nt-long in the $5^{\prime}$-end, mediates its interaction with target mRNAs and determines the target specificity. It usually binds to the $3^{\prime}$-untranslated regions ( $3^{\prime}$-UTRs) of specific mRNAs to affect their mRNA stability or protein translation (14). Significant progresses have been made in assessing the biological activities and regulation of miR-124, including experimental validation of a number of predicted targets and the unveiling of regulatory mechanism. Thus, it is possible now to comprehend the roles of miR-124 in innate and specific immunity as well as immunity and inflammation-associated diseases. 


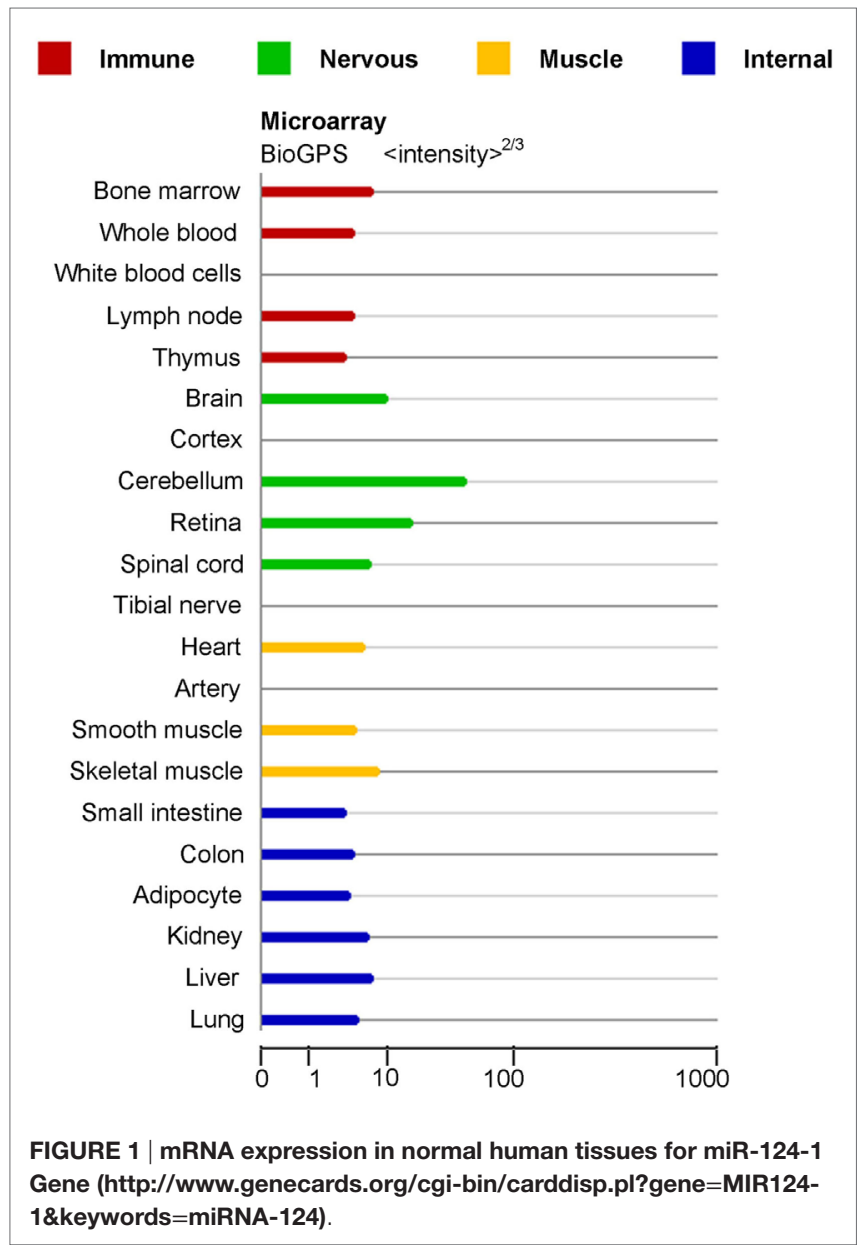

\section{miR-124 IN THE INNATE AND ADAPTIVE IMMUNE CELLS}

\section{miR-124 in Hematopoietic Cells}

miRNAs have been demonstrated to regulate hematopoiesis through targeting different genes post-transcriptionally (15). Recently, miR-124 is found to be expressed in a low level in human cord blood CD34(+) cells, but considerably upregulated during culturing and differentiation of these cells. Moreover, miR-124 decreases Tip110 expression and promotes differentiation of human cord blood CD34(+) cells, suggesting an important role of miR-124/Tip110 in hematopoiesis (16).

\section{miR-124 in the Dendritic Cell Subsets}

miR-124 is likely involved in the process of dendritic cell (DC) subset development. DCs include plasmacytoid DCs (pDCs) and classical DCs (cDCs) subpopulations, with the latter consisting of $\mathrm{CDC} 1$ and $\mathrm{cDC} 2$ lineages. DC subsets from the culture of mouse bone marrow showed high expression of miR-124, which is dominantly expressed in CD24(+) cDC1 cells compared with pDCs and CD $172 \alpha^{+} \mathrm{cDC} 2$ cells. miR-124 is supposed to be involved in the processes of DC subset development by targeting the transcript of TCF4, a critical transcription factor in the development and homeostasis of pDCs (17).

\section{miR-124 in the Resident Macrophage Polarization}

Macrophages function depending on polarization status. M1 macrophages are characterized by a proinflammatory phenotype, while M2 macrophages display anti-inflammatory one $(18,19)$. It has been reported that resident macrophages nest in various tissues including the central nervous system (CNS), peritoneum, lungs, liver, and adipose tissues. They express a number of M2 markers, such as Ym1, IL-10, IL-4, CD206, Fizz1, and Arg1, suggesting that tissue-resident macrophages are often M2 dominant under normal physiological conditions (20). miR-124 is essential for the induction and maintenance of the M2 phenotype in tissue-resident macrophages, as reflected by miR-124 inhibitor abrogating the upregulation of M2 markers (CD206, Ym1) and downregulation of M1 markers (CD86, iNOS, TNF) in M2-polarized macrophages (21). miR-124 serves as a universal regulator of $\mathrm{M} 2$ macrophage polarization, and $\mathrm{C} / \mathrm{EBP}-\alpha$ is regarded as the mediator of the miR-124 effect on macrophage polarization, although it remains unclear how C/EBP- $\alpha$ suppresses M2 polarization (22).

\section{miR-124 in the CD4 ${ }^{+} \mathrm{T}$ Cell Differentiation}

miR-124 is a critical mediator for the differentiation of naïve CD4 ${ }^{+}$ T cells into T helper type $1[\mathrm{~T}(\mathrm{H}) 1]$ and $\mathrm{T}(\mathrm{H}) 17$ cells in vitro and in vivo, which is regulated by the upstream methyl CpG-binding protein 2 (MeCP2) protein. Loss of MeCP2 in $\mathrm{CD}^{+} \mathrm{T}$ cells results in the decreased expression of miR-124, with consequently the accumulation of miR-124-targeting protein suppressor of cytokine signaling 5 (SOCS5). SOCS5 then inhibits STAT1 and STAT3 activation, further represses the differentiation of T(H)1 and $\mathrm{T}(\mathrm{H}) 17$ cells, respectively (23).

\section{miR-124 IN THE IMMUNE RESPONSES}

\section{miR-124 in Innate Immune Responses}

The innate immune system coordinates host defenses through pattern recognition receptors, such as toll-like receptors (TLRs) (24). miRNAs represent a component of the innate immune responses that can restrain inflammatory signaling $(1,25,26)$. It is reported that miR-124 can be induced upon Mycobacterium bovis bacillus Calmette-Guérin (BCG) infection in both RAW264.7 AM cells in vitro and murine AMs in vivo and is transcriptionally regulated by TLR signaling adaptor MyD88. In turn, elevated miR-124 negatively modulates TLR activity in RAW264.7 cells by directly targeting multiple components of TLR signaling cascade, including the TLR6, myeloid differentiation factor 88 (MyD88), TNFR-associated factor 6 (TRAF6), and TNF- $\alpha$ (27). Moreover, our lab also found activation of TLR4 rapidly increased the level of miR-124 in RAW264.7 macrophages and mice, while miR-124 directly targeted ubiquitin-specific proteases 2 (USP2) and 14 (USP14), two components of deubiquitinating enzymes, to negatively regulate LPS-induced production of TNF- $\alpha$ at the post-transcriptional 
level (28). Opioids have universal immunosuppressive effects, and the mechanisms are unclear. Qiu et al. have found morphine inhibits the innate immunity in microglia partially through TLRs, and miR-124 mediates this effect. Morphine promotes miR-124 expression in microglia, bone marrow-derived macrophages through upregulating p65 expression, which can directly bind to promoters of miR-124 and enhance miR-124 transcription, where miR-124 mediates morphine's inhibition of the TLR signaling by directly targeting a subunit of NF- $\mathrm{KB}$ p65 and TRAF6 (29).

The cholinergic anti-inflammatory pathway is a type of neurophysiological regulatory mechanism to the immune stimulus, capable of monitoring, and feedback adjusting body inflammatory responses. When meeting inflammatory challenge, the vagus nerve releases acetylcholine, the principal neurotransmitter, to ameliorate the synthesis and release of inflammatory cytokines and guard against tissue damage through the $\alpha 7$ subunit-containing nicotinic acetylcholine receptors ( $\alpha 7 \mathrm{nAChRs)}$ in the macrophages. Our lab found that miR-124 is a critical mediator for the cholinergic antiinflammatory action. miR-124 is upregulated by cholinergic agonists in LPS-exposed cells and mice, and miR-124 further modulates TLR4-induced cytokine production by targeting signal transducer and activator of transcription 3 (STAT3) to decrease IL- 6 production and TNF- $\alpha$ converting enzyme (TACE) to reduce TNF- $\alpha$ release (30). These results indicate a negative regulatory role of miR-124 in fine-tuning the TLRtriggered inflammatory responses.

\section{miR-124 in Adaptive Immune Responses}

$T$ lymphocytes are the main executors of the adaptive immune responses. miR-124 is reported to exert potent anti-glioma therapeutic effects via a T cell-mediated antitumor immune response. Glioma cancer stem cells (gCSCs) produce immunosuppressive roles in the T-cell proliferation, and miR-124 could reverse this suppressive effect and decrease the generation of Foxp $3^{+}$regulatory T-cells (Tregs). Furthermore, treatment of T-cells with miR124 induces marked effector response including the upregulation of IL-2, IFN- $\gamma$, and TNF- $\alpha$. STAT3, a key pathway mediating immunosuppression in the tumor microenvironment, is identified as the target of miR-124 in the regulation of T-cell functions. In addition, miR-124 also modulates T-helper cell differentiation. When miR-124 is overexpressed, IL-17A $+\mathrm{T}_{\mathrm{H}} 17$ cells and FoxP3 ${ }^{+}$ Treg induction is inhibited, whereas IFN $-\gamma+\mathrm{T}_{\mathrm{H}} 1$ cells differentiation is strengthened (31).

miR-124 also mediates the effect of IL-7 in the generation and maintenance of memory $\mathrm{T}$ cells and benefits survival and expansion of HIV-1-latently infected memory $\mathrm{CD} 4^{+} \mathrm{T}$ lymphocytes. IL-7 could elevate miR-124 level, which targets and downregulates polypyrimidine tract-binding protein (PTB) and subsequently leads to the elevation of CD95 on memory CD4 ${ }^{+} \mathrm{T}$ cells. Elevated CD95, combined with coactivated FLICE-like inhibitory protein (c-FLIP) and JNK by IL-7, primes $\mathrm{CD}^{+} \mathrm{T}$ lymphocytes to a survival mode and contributes to the IL-7-mediated maintenance of HIV-1 reservoir (32).

Critical illness-related corticosteroid insufficiency (CIRCI) is defined as inadequate corticosteroid activity for the severity of the illness. Sepsis is often accompanied with acquired glucocorticoid resistance, which complicates the therapy of sepsis. T-cell system is the key player in the adaptive immune response and is considered as one of the key players in the pathogenesis of CIRCI. Recent studies showed that miR-124 mediates the glucocorticoid resistance in human T-cells. T-cells from sepsis patients exhibit decreased glucocorticoid receptor- $\alpha$ (mediating anti-inflammatory effects) and increased miR-124 levels. Further studies demonstrated that glucocorticoid significantly elevates miR-124 level, which specifically downregulates glucocorticoid receptor- $\alpha$ and limits anti-inflammatory effects of glucocorticoids (33).

\section{miR-124 IN IMMUNE DISEASES}

Many inflammatory diseases and immune disorders witness altered miR-124 expression. Further characterization of these regulatory networks triggers mechanistic studies. The involvement of miR-124 in immunity-related diseases and their identified targets are discussed in detail as followed.

\section{miR-124 in CNS Immune-Related Diseases}

miR-124 is one type of brain-specific miRNAs and has been revealed to mediate the function of immune system in the CNS $(12,34)$. miR-124 was first identified as a key regulator of promoting microglia, one kind of macrophages that are resident in the brain and spinal cord, quiescence. miR-124 expression is decreased in activated microglia during the course of experimental autoimmune encephalomyelitis (EAE), while overexpression of miR-124 could promote activated microglia into a phenotype resembling resting microglia and suppress EAE by deactivating macrophages via the C/EBP- $\alpha$-PU.1 pathway (22). Spinal cord injury remains a difficulty to be treated due to the secondary inflammatory damage induced by activated microglia and/or macrophages. Louw et al. found that miR-124 transfection decreased the activation of rat microglia. Microinjected particles of chitosan/miR-124 in the peritoneum, which will be transported by macrophages to the site of spinal cord injury $72 \mathrm{~h}$ post injection, decrease the infiltration of macrophages in the injured spinal cord, and therefore ameliorate spinal cord injury (35). Chronic pain is often associated with microglia activation in the spinal cord. Willemen et al. have found that persistent hyperalgesia in LysM-GRK2 $2^{+/}$mice is associated with reduced miR-124 levels in spinal cord microglia, while intrathecal miR-124 treatment can be used to prevent and treat persistent inflammatory and neuropathic pain by restoring the increased ratio of M1/M2 type markers in spinal cord microglia/ macrophages (36).

However, miR-124 does not always act as a repressor for microglia activation. Epilepsy is closely relevant to dysregulated inflammatory pathways. Brennan et al. have proved that status epilepticus leads to suppressed miR-124 expression, while synthetic miR-124 significantly augments microglia activation and inflammatory cytokines. Further studies have demonstrated that miR-124 acts as a dual regulator in epilepsy, which attenuates epileptogenesis via targeting NRSF while promoting epilepsy via exaggerating inflammation (37). 


\section{miR-124 in Peripheral Immune-Related Diseases}

Inflammatory bowel diseases (IBDs), which refer to ulcerative colitis (UC) and Crohn's disease (CD), are multifactorial diseases with probable genetic heterogeneity. Environmental risk factors, such as diet, smoking, measles, or appendectomy, may contribute to their pathogenesis. The mechanism of IBDs has only been partly understood. Recent reports indicated that miR-124 might be involved in their regulation. Koukos et al. found that miR124 is downregulated in tissues from children with UC due to promoter hypermethylation, while reduced levels of miR-124 promote inflammation and the pathogenesis of UC by increasing expression and activity of STAT3 in colon tissues. Interestingly, the same group did not observe the decrease of miR-124 in adult UC tissues, reflecting the mechanistic differences between adults and pediatric UC (38). Inversely, active CD patients were found to have higher level of miR-124 in colon tissues and intestinal epithelial cells (IECs). miR-124 can directly target AHR protein to modulate proinflammatory cytokine production and thereby promote the pathogenesis of $\mathrm{CD}(39,40)$. As we know, smoking plays a dual role in IBD by decreasing the risk of UC and increasing that of $\mathrm{CD}(41)$, the potential mechanisms are still unknown. It has been reported that nicotine is thought to be the most important agent responsible for the effect of smoking, and the dual role of miR-124 in the treatment of UC and CD may be responsible for this discrepancy, which needs to be further explored.

Rheumatoid arthritis (RA) is an autoimmune disease in which the body's immune system mistakenly attacks the joints. It is recently reported that RA patients have higher miR-124 promoter methylation, while healthy controls have not such a modification, suggesting that epigenetic dysregulation may be involved in the development of RA (42). Moreover, Nakamachi et al. found that miR-124 level significantly decreased in RA synoviocytes as compared with osteoarthritis (OA) synoviocytes, and miR-124 could target cyclin-dependent kinase 2 (CDK2) or monocyte chemotactic protein 1 (MCP1), adjusting proliferation and the ability to produce chemokines of fibroblast-like synovial cells (43). Subsequently, they also found that forced expression of miR-124 repressed adjuvant-induced arthritis (AIA) in rats by suppressing RANKL and NFATc1, resulting in the decreased synoviocyte proliferation, leukocyte infiltration, and cartilage or bone destruction (44). Thus, miR-124 is a promising therapeutic target in human RA.

Ankylosing spondylitis (AS) is a type of arthritis that affects the spine, and symptoms include pain and stiffness from the neck down to the lower back. The spine's bones (vertebrae) may grow or fuse together, resulting in a rigid spine. miR-124 is upregulated and ANTXR2 is downregulated in peripheral blood from AS patients. Further studies demonstrated that miR-124 targeted ANTXR2 and inhibited its expression in Jurkat cells, leading to the activation of JNK and inducing autophagy. miR-124-ANTXR2 might be a therapeutic target for AS (45).

\section{miR-124 in Tumor Immunity}

Many studies have demonstrated the potential application of miR-124 as a novel immunotherapeutic agent for tumors, and several targets have been identified. For example, miR-124 can inhibit tumor by directly targeting STAT3, a key component mediating immunosuppression in the tumor microenvironment. Bellon et al. found miR-124 inhibited adult T-cell leukemia (ATL) cell proliferation in vitro and tumor growth in vivo of ATL mouse model by targeting STAT3-Pim1 pathway (46). Wei et al. reported that systemic administration of miR-124 or adoptive miR-124-transfected T-cell-suppressed glioma by repressing the STAT3 pathway (31). miR-124 can suppress the fitness of B-cell lymphomas by targeting MYC and BCL2, which are coexpressed in B-cell lymphomas and associated with the poor prognosis (47). Meanwhile, miR-124 also increases sensitivity of B-cell lymphomas to glucocorticoid treatment by targeting phosphodiesterase $4 \mathrm{~B}$ (PDE4B) and may act as an attractive therapeutic target in $\mathrm{B}$ cell lymphoma (48).

miR-124 can exert tumor suppressive effects in human liver cancers. Hepatocyte nuclear factor $4 \alpha$ (HNF $4 \alpha$ ) reduction contributes to liver tumorigenesis and inflammation. Hatziapostolou et al. reported that miR-124 is an integral part of the circuit and a direct downstream effector of HNF4 $\alpha$ activity, targeting IL-6R, and modulating IL-6R/STAT3 pathway during hepatocellular transformation. Systemic administration of miR-124 suppresses hepatocellular carcinogenesis by inducing tumor-specific apoptosis (49). Coincidentally, Ning et al. have reported that miR-124 also participates in HNF4 $\alpha-\mathrm{NF}-\mathrm{kB}$ feedback circuit in hepatocellular carcinoma. miR-124 is elevated by HNF4 $\alpha$ transcriptionally, inhibiting RelA (p65) expression via interaction with RelA-3'-UTR (50). Intriguingly, an activated NF- $\mathrm{\kappa B}$-centered inflammatory loop was also detected in node-positive non-small cell lung carcinoma (NSCLC). NF- $\mathrm{kB}$ regulated miR-124 targets MYO10, inhibiting cell invasion and metastasis (51).

Particularly, miR-124 is known to be methylation silenced during exposure to chronic inflammation, which is correlated with the higher epidemiologic risk of cancer. Ueda et al. have reported that three miR-124 genes are methylated, whereas CDK6 is highly expressed in tissues from patients with colitisassociated cancer (CAC), sporadic colorectal cancer, and dysplasia. During carcinogenesis in UC patients, miR-124 genes are methylated. The methylation level of miR-124-3 could be recognized as a valuable marker for estimating individual risk of CAC (52). Methylation of hsa-miR-124-2 was previously found to be indicative for cervical (pre)cancer. Methylation markers combined with HPV testing might offer a full molecular screening strategy to the many HIV-infected women who are also hrHPV-positive (53).

\section{miR-124 in Viral Immunity}

Several studies have revealed alterations in cellular miRNA profiles following HIV-1 infection, which are mostly involved in inhibiting viral infection. However, several miRNAs, including miR-124, were found to modulate viral spread in T-lymphocytes and HeLa-CCR5 cell lines. Following infection, let-7c, miR-34a, or miR-124 was upregulated, and they targeted and downregulated p21 and TASK1, which eventually led to increased virion release and higher copy number of viral genome transcripts in infected cells, suggesting that HIV-1 
TABLE 1 | miR-124 in immune system and immune disorders.

\begin{tabular}{|c|c|c|c|c|}
\hline $\begin{array}{l}\text { Physiological and } \\
\text { pathological conditions }\end{array}$ & Expression & Target & Action & Reference \\
\hline Hematopoiesis differentiation & $\begin{array}{l}\text { Upregulation in the differentiation of } \\
\text { human cord blood CD34(+) cells }\end{array}$ & Tip110 & Regulate hematopoiesis differentiation & $(16)$ \\
\hline DC subset development & $\begin{array}{l}\text { High expression in CD24(+) cDC1 } \\
\text { cells during the culture of mouse } \\
\text { bone marrow }\end{array}$ & TCF4 & Regulate DC subset development & $(17)$ \\
\hline $\begin{array}{l}\text { Resident macrophage } \\
\text { polarization }\end{array}$ & $\begin{array}{l}\text { Constitutive expression in } \\
\text { macrophages }\end{array}$ & - & $\begin{array}{l}\text { Promote M2 polarization of resident } \\
\text { macrophages }\end{array}$ & $(21)$ \\
\hline $\begin{array}{l}\text { Experimental autoimmune } \\
\text { encephalomyelitis (EAE) }\end{array}$ & $\begin{array}{l}\text { Downregulation in activated } \\
\text { microglia }\end{array}$ & C/EBP- $\alpha-P U .1$ & $\begin{array}{l}\text { Promote microglia quiescence and protect } \\
\text { against EAE }\end{array}$ & $(22)$ \\
\hline $\mathrm{CD}^{+}{ }^{+} \mathrm{T}$ cell differentiation & $\begin{array}{l}\text { Upregulation in the process } \\
\text { of CD4+ } \mathrm{T} \text { cell differentiation }\end{array}$ & SOCS5 & $\begin{array}{l}\text { Stimulate naïve } C D 4^{+} T \text { cells to differentiate into } \\
T \text { helper type } 1[T(H) 1] \text { and } T(H) 17 \text { cells }\end{array}$ & (23) \\
\hline BCG infection & $\begin{array}{l}\text { Upregulation in alveolar macrophages } \\
\text { upon BCG infection }\end{array}$ & $\begin{array}{l}\text { TLR6, MyD88, } \\
\text { TRAF6, and TNF- } \alpha\end{array}$ & Restrain inflammatory signaling & $(27)$ \\
\hline TLR4 signaling & $\begin{array}{l}\text { Upregulation in LPS-stimulated } \\
\text { RAW264.7 macrophages and mice }\end{array}$ & USP2, USP14 & Negatively regulate TNF- $\alpha$ production & $(28)$ \\
\hline $\begin{array}{l}\text { Morphine's effect in innate } \\
\text { immunity }\end{array}$ & $\begin{array}{l}\text { Upregulation in microglia and } \\
\text { macrophages treated by morphine }\end{array}$ & $\begin{array}{l}\mathrm{NF}-\kappa \mathrm{B} \text { p } 65 \text { and } \\
\text { TRAF6 }\end{array}$ & Mediate morphine's inhibition in the TLR signaling & (29) \\
\hline $\begin{array}{l}\text { Cholinergic anti- } \\
\text { inflammation pathway }\end{array}$ & Upregulation by cholinergic agonists & STAT3 and TACE & $\begin{array}{l}\text { Critical mediator for the cholinergic anti- } \\
\text { inflammatory action }\end{array}$ & (30) \\
\hline Gliomas & $\begin{array}{l}\text { Absence in all grades and } \\
\text { pathological types of gliomas }\end{array}$ & $\begin{array}{l}\text { STAT3 in T cells and } \\
\text { in glioma cancer stem } \\
\text { cells (gCSC) }\end{array}$ & Anti-glioma effects & (31) \\
\hline $\begin{array}{l}\text { Corticosteroid resistance in } \\
\text { sepsis }\end{array}$ & $\begin{array}{l}\text { Upregulation by glucocorticoid } \\
\text { in T cells }\end{array}$ & GR- $\alpha$ & Limit anti-inflammatory effects of glucocorticoids & (33) \\
\hline Spinal cord injury & Forced expression & - & $\begin{array}{l}\text { Decrease microglia activation and ameliorate } \\
\text { spinal cord injury }\end{array}$ & (35) \\
\hline Chronic pain & $\begin{array}{l}\text { Downregulation in spinal cord } \\
\text { microglia }\end{array}$ & - & $\begin{array}{l}\text { Increase the ratio of } \mathrm{M} 1 / \mathrm{M} 2 \text { type markers, and } \\
\text { prevent or treat chronic pain }\end{array}$ & $(36)$ \\
\hline Status epilepticus & Downregulation & $\begin{array}{l}\text { Inhibit NRSF and } \\
\text { augment microglia } \\
\text { activation }\end{array}$ & $\begin{array}{l}\text { Attenuate epileptogenesis via targeting NRSF } \\
\text { while promote epilepsy via exaggerating } \\
\text { inflammation }\end{array}$ & $(37)$ \\
\hline Ulcerative colitis (UC) & $\begin{array}{l}\text { Downregulation in colon tissues } \\
\text { from children with UC }\end{array}$ & STAT3 & Inhibit inflammation and the pathogenesis of $U C$ & (38) \\
\hline Crohn's disease (CD) & $\begin{array}{l}\text { Upregulation in colon tissues and } \\
\text { intestinal epithelial cells }\end{array}$ & AHR & $\begin{array}{l}\text { Modulate proinflammatory cytokine production } \\
\text { and promote the pathogenesis of } C D\end{array}$ & $(40)$ \\
\hline Rheumatoid arthritis (RA) & Downregulation in RA synoviocytes & $\begin{array}{l}\text { CDK-2, MCP-1, } \\
\text { NFATc1, and RANKL }\end{array}$ & $\begin{array}{l}\text { Decrease synoviocyte proliferation, leukocyte } \\
\text { infiltration and cartilage or bone destruction, and } \\
\text { protect against RA }\end{array}$ & $(43,44)$ \\
\hline Ankylosing spondylitis (AS) & $\begin{array}{l}\text { Upregulation in peripheral blood } \\
\text { from AS patients }\end{array}$ & ANTXR2 & Therapeutic action for AS & $(45)$ \\
\hline Adult T-cell leukemia (ATL) & Downregulation & STAT3-Pim1 & $\begin{array}{l}\text { Inhibit ATL-cell proliferation and tumor growth of } \\
\text { ATL mouse model }\end{array}$ & $(46)$ \\
\hline \multirow[t]{2}{*}{ B-cell lymphomas (BCL) } & Downregulation & $\begin{array}{l}\text { P65 } \\
\text { MYC } \\
\text { BCL2 }\end{array}$ & Suppress the fitness of BCL & $(47)$ \\
\hline & & PDE4B & Increase sensitivity of BCL to glucocorticoid & $(48)$ \\
\hline Liver cancers & $\begin{array}{l}\text { Downregulation in hepatocellular } \\
\text { oncogenesis }\end{array}$ & IL-6R and P65 & Tumor suppressive effects & $(49,50)$ \\
\hline $\begin{array}{l}\text { Non-small cell lung carcinoma } \\
\text { (NSCLC) }\end{array}$ & $\begin{array}{l}\text { Downregulation in highly invasive } \\
\text { sub-cell lines and node-positive } \\
\text { NSCLC specimens }\end{array}$ & MYO10 & Inhibit cell invasion and metastasis & $(51)$ \\
\hline Colitis-associated cancer (CAC) & $\begin{array}{l}\text { Methylation in tissues from patients } \\
\text { with CAC }\end{array}$ & CDK6 & $\begin{array}{l}\text { The methylation level of miR-124-3 is a promising } \\
\text { marker for estimating individual risk of CAC }\end{array}$ & $(52)$ \\
\hline Cervical (pre)cancer & Methylation & - & Indication of cervical (pre)cancer & (53) \\
\hline
\end{tabular}


TABLE 1 | Continued

\begin{tabular}{|c|c|c|c|c|}
\hline $\begin{array}{l}\text { Physiological and } \\
\text { pathological conditions }\end{array}$ & Expression & Target & Action & Reference \\
\hline \multirow[t]{2}{*}{ HIV-1 infection } & Upregulation following infection & p21 and TASK1 & $\begin{array}{l}\text { Increase viral spread in T-lymphocytes and HeLa- } \\
\text { CCR5 cell lines }\end{array}$ & $(54)$ \\
\hline & Upregulation by IL-7 & PTB & $\begin{array}{l}\text { Benefit survival and expansion of HIV-1-latently } \\
\text { infected memory CD4+ T lymphocytes }\end{array}$ & $(32)$ \\
\hline $\begin{array}{l}\text { A/Swine/GD/2/12 ( } \mathrm{H} 1 \mathrm{~N} 1) \text { virus } \\
\text { infection }\end{array}$ & Upregulation & $\begin{array}{l}\text { Innate immunity- } \\
\text { related pathways }\end{array}$ & Pathway analysis & $(55)$ \\
\hline Enterovirus 71 (EV71) infection & Upregulation & - & Indicate virus and the host interaction & $(56)$ \\
\hline HCMV latent infection & Upregulation of hsa miR-124-3p & - & - & $(57)$ \\
\hline
\end{tabular}

could utilize the host miRNA cellular systems to produce a more efficient infection process via blocking the mechanism of innate inhibition (54). Additional studies have demonstrated this regulation. Through inducing miR-124, IL-7 has been shown to elevate CD95 in CD4(+) T cells from HIV-1-infected individuals and prime CD4(+) T lymphocytes to CD95mediated signals, leading to the IL-7-mediated maintenance of HIV-1 reservoir (32).

miRNA deep sequencing was performed to probe into the contribution of miRNAs to the host immune response to virus infection. Intriguingly, pathway analysis of miRNAs and targets has shown that increased miR-124-3p interplays with innate immunity-related pathways in spleen tissues of mice infected with A/Swine/GD/2/12 (H1N1) virus. Further master of the roles played by these miRNAs in influenza virus infection will acquire a good comprehension of host-pathogen interactions (55).

Bian et al. found miR-124 specifically responded to the Enterovirus 71 (EV71) infection and interferon (IFN) treatment, and they further predicted some related signaling pathways, which would be helpful to elucidate the interaction between the virus and the host (56). In addition, the expression of hsa miR-124-3p is significantly upregulated in the HCMV latent infection library (57). Japanese encephalitis virus (JEV) can infect neurons and directly cause lethal encephalitis. Yen et al. inserted two copies of a perfectly matched miR-124 recognition element into the $3^{\prime}$-UTR of viral RNA to create infectious JEV recombinant RP-124PT (rRP-124PT). The effect of $\mathrm{rRP}-124 \mathrm{PT}$ was attenuated in infected mice as compared with MRE mutant and parental strains. Immunization with rRP-124PT appeared to elicit full protective immunity against subsequent JEV lethal challenge, indicating that endogenous neuron-specific miR-124 could be used to restrict viral neurotropism and consequently diminish the neurovirulence of JEV in mice (58).

\section{CONCLUSION AND PERSPECTIVES}

Large numbers of studies in different cells and systems have found that miR-124 is a critical modulator of immune cells, inflammatory, and immunological responses. In many cases, miR-124 is induced by the inflammatory or immunological signals and, in turn, functions as a negative regulator for these signals, forming a negative feedback to help maintain homeostasis. Physiological and pathological changes and their significance of miR-124 are summarized in Table 1. Noteworthily, it has been demonstrated that a particular miRNA could often target multiple proteins, and a particular protein might be regulated by multiple miRNAs. Therefore, algorithm analysis based on miRNA profile as well as molecules in activated signal pathway will likely provide a more comprehensive picture for understanding the regulatory action of miRNA (56). Such analysis may also shed new insight on the roles of miR-124 in infectious and immunological diseases.

The alterations of miR-124 have been found in many inflammatory and immunological diseases. Therefore, assessing miR-124 in various body fluids (59-61) might be an informative biomarker for the timely diagnosis and prognosis of inflammatory diseases. Additionally, stable miR-124 mimic and inhibitor are candidates for therapeutics that modulate inflammatory and immunological diseases. Thus, further exploring the specific roles of miR-124 under physiological and pathological conditions may likely bear fruitful results in the foreseeable future.

Recently, a report has aroused widespread attention that precursor miRNAs could compete with their mature miRNA counterparts. Roy-Chaudhuri et al. validated this for miR-124 and the SNAI2 3'-UTR. Therefore, miR-124 precursors are expected to serve as post-transcriptional regulators of miRNA activities rather than mere biogenesis midbodies (62). The regulatory role of miR-124 precursors in immune regulation might be a novel research frontier.

\section{AUTHOR CONTRIBUTIONS}

ZQ and P-YW retrieved and analyzed concerned literatures. ZQ wrote the manuscript. XL and D-FS revised the manuscript. All authors agree to be accountable for the content of the work.

\section{FUNDING}

This study was supported by grants from the National Natural Science Foundation of China (81273606 and 81473259 to XL, 81230083 to D-FS) and National Science and Technology Major Project (2014ZX09J14103-08C to XL). 


\section{REFERENCES}

1. Mehta A, Baltimore D. microRNAs as regulatory elements in immune system logic. Nat Rev Immunol (2016) 16(5):279-94. doi:10.1038/nri.2016.40

2. Lee Y, Kim M, Han J, Yeom KH, Lee S, Baek SH, et al. microRNA genes are transcribed by RNA polymerase II. EMBO J (2004) 23(20): 4051-60. doi:10.1038/sj.emboj.7600385

3. Ambros V. The functions of animal microRNAs. Nature (2004) 431(7006): 350-5. doi:10.1038/nature02871

4. Bartel DP. microRNAs: target recognition and regulatory functions. Cell (2009) 136(2):215-33. doi:10.1016/j.cell.2009.01.002

5. Han J, Lee Y, Yeom KH, Nam JW, Heo I, Rhee JK, et al. Molecular basis for the recognition of primary microRNAs by the Drosha-DGCR8 complex. Cell (2006) 125(5):887-901. doi:10.1016/j.cell.2006.03.043

6. Filios SR, Shalev A. $\beta$-Cell microRNAs: small but powerful. Diabetes (2015) 64(11):3631-44. doi:10.2337/db15-0831

7. Winter J, Jung S, Keller S, Gregory RI, Diederichs S. Many roads to maturity: microRNA biogenesis pathways and their regulation. Nat Cell Biol (2009) 11(3):228-34. doi:10.1038/ncb0309-228

8. Shenoy A, Blelloch RH. Regulation of microRNA function in somatic stem cell proliferation and differentiation. Nat Rev Mol Cell Biol (2014) 15(9):565-76. doi:10.1038/nrm3854

9. Raza U, Zhang JD, Şahin O. microRNAs: master regulators of drug resistance, stemness, and metastasis. J Mol Med (Berl) (2014) 92(4):321-36. doi:10.1007/ s00109-014-1129-2

10. Han W, Fu X, Xie J, Meng Z, Gu Y, Wang X, et al. miR-26a enhances autophagy to protect against ethanol-induced acute liver injury. J Mol Med (Berl) (2015) 93(9):1045-55. doi:10.1007/s00109-015-1282-2

11. Lagos-Quintana M, Rauhut R, Yalcin A, Meyer J, Lendeckel W, Tuschl T. Identification of tissue-specific microRNAs from mouse. Curr Biol (2002) 12(9):735-9. doi:10.1016/S0960-9822(02)00809-6

12. Papagiannakopoulos T, Kosik KS. microRNA-124: micromanager of neurogenesis. Cell Stem Cell (2009) 4(5):375-6. doi:10.1016/j.stem.2009.04.007

13. Smerkova K, Hudcova K, Vlahova V, Vaculovicova M, Pekarik V, Masarik M, et al. Label-free and amplification-free miR-124 detection in human cells. Int J Oncol (2015) 46(2):871-7. doi:10.3892/ijo.2014.2756

14. Iwakawa HO, Tomari Y. The functions of microRNAs: mRNA decay and translational repression. Trends Cell Biol (2015) 25(11):651-65. doi:10.1016/j. tcb.2015.07.011

15. Chen CZ, Li L, Lodish HF, Bartel DP. microRNAs modulate hematopoietic lineage differentiation. Science (2004) 303(5654):83-6. doi:10.1126/ science.1091903

16. Liu Y, Huang X, Timani KA, Broxmeyer HE, He JJ. microRNA-124 targets Tip110 expression and regulates hematopoiesis. Stem Cells Dev (2015) 24(17):2009-17. doi:10.1089/scd.2015.0030

17. Han SM, Na HY, Ham O, Choi W, Sohn M, Ryu SH, et al. TCF4-targeting miR-124 is differentially expressed amongst dendritic cell subsets. Immune Netw (2016) 16(1):61-74. doi:10.4110/in.2016.16.1.61

18. Gordon S, Martinez FO. Alternative activation of macrophages: mechanism and functions. Immunity (2010) 32(5):593-604. doi:10.1016/j.immuni. 2010.05.007

19. Murray PJ, Allen JE, Biswas SK, Fisher EA, Gilroy DW, Goerdt S, et al. Macrophage activation and polarization: nomenclature and experimental guidelines. Immunity (2014) 41(1):14-20. doi:10.1016/j.immuni.2014.06.008

20. Satoh T, Kidoya H, Naito H, Yamamoto M, Takemura N, Nakagawa K, et al. Critical role of Trib1 in differentiation of tissue-resident M2-like macrophages. Nature (2013) 495(7442):524-8. doi:10.1038/nature11930

21. Veremeyko T, Siddiqui S, Sotnikov I, Yung A, Ponomarev ED. IL-4/IL-13dependent and independent expression of miR-124 and its contribution to M2 phenotype of monocytic cells in normal conditions and during allergic inflammation. PLoS One (2013) 8(12):e81774. doi:10.1371/journal.pone.0081774

22. Ponomarev ED, Veremeyko T, Barteneva N, Krichevsky AM, Weiner HL. microRNA-124 promotes microglia quiescence and suppresses EAE by deactivating macrophages via the C/EBP-[alpha]-PU.1 pathway. Nat Med (2011) 17(1):64-70. doi:10.1038/nm.2266

23. Jiang S, Li C, McRae G, Lykken E, Sevilla J, Liu SQ, et al. MeCP2 reinforces STAT3 signaling and the generation of effector CD4+ T cells by promoting miR-124-mediated suppression of SOCS5. Sci Signal (2014) 7(316):ra25. doi:10.1126/scisignal.2004824
24. Murray PJ, Smale ST. Restraint of inflammatory signaling by interdependent strata of negative regulatory pathways. Nat Immunol (2012) 13(10):916-24. doi:10.1038/ni.2391

25. Forster SC, Tate MD, Hertzog PJ. microRNA as type I interferon-regulated transcripts and modulators of the innate immune response. Front Immunol (2015) 6:334. doi:10.3389/fimmu.2015.00334

26. Yang CR, Shih KS, Liou JP, Wu YW, Hsieh IN, Lee HY, et al. Denbinobin upregulates miR-146a expression and attenuates IL-1 $\beta$-induced upregulation of ICAM-1 and VCAM-1 expressions in osteoarthritis fibroblast-like synoviocytes. J Mol Med (Berl) (2014) 92(11):1147-58. doi:10.1007/s00109014-1192-8

27. Ma C, Li Y, Li M, Deng G, Wu X, Zeng J, et al. microRNA-124 negatively regulates TLR signaling in alveolar macrophages in response to mycobacterial infection. Mol Immunol (2014) 62(1):150-8. doi:10.1016/j. molimm.2014.06.014

28. Sun Y, Qin Z, Li Q, Wan JJ, Cheng MH, Wang PY, et al. microRNA-124 negatively regulates LPS-induced TNF- $\alpha$ production in mouse macrophages by decreasing protein stability. Acta Pharmacol Sin (2016) 37(7):889-97. doi:10.1038/aps.2016.16

29. Qiu S, Feng Y, LeSage G, Zhang Y, Stuart C, He L, et al. Chronic morphine-induced microRNA-124 promotes microglial immunosuppression by modulating P65 and TRAF6. J Immunol (2015) 194(3):1021-30. doi:10.4049/ jimmunol.1400106

30. Sun Y, Li Q, Gui H, Xu DP, Yang YL, Su DF, et al. microRNA-124 mediates the cholinergic anti-inflammatory action through inhibiting the production of pro-inflammatory cytokines. Cell Res (2013) 23(11):1270-83. doi:10.1038/ cr.2013.116

31. Wei J, Wang F, Kong LY, Xu S, Doucette T, Ferguson SD, et al. miR-124 inhibits STAT3 signaling to enhance T cell-mediated immune clearance of glioma. Cancer Res (2013) 73(13):3913-26. doi:10.1158/0008-5472.CAN$12-4318$

32. Yin $\mathrm{Y}$, Zhang S, Luo H, Zhang X, Geng G, Li J, et al. Interleukin 7 up-regulates CD95 protein on $\mathrm{CD} 4+\mathrm{T}$ cells by affecting mRNA alternative splicing: priming for a synergistic effect on HIV-1 reservoir maintenance. J Biol Chem (2015) 290(1):35-45. doi:10.1074/jbc.M114.598631

33. Ledderose C, Mohnle P, LimbeckE, Schutz S, Weis F, RinkJ, et al. Corticosteroid resistance in sepsis is influenced by microRNA-124-induced downregulation of glucocorticoid receptor- $\alpha$. Crit Care Med (2012) 40(10):2745-53. doi:10.1097/CCM.0b013e31825b8ebc

34. Soreq $\mathrm{H}$, Wolf Y. NeurimmiRs: microRNAs in the neuroimmune interface. Trends Mol Med (2011) 17(10):548-55. doi:10.1016/j.molmed.2011.06.009

35. Louw AM, Kolar MK, Novikova LN, Kingham PJ, Wiberg M, Kjems J, et al. Chitosan polyplex mediated delivery of miRNA-124 reduces activation of microglial cells in vitro and in rat models of spinal cord injury. Nanomedicine (2016) 12(3):643-53. doi:10.1016/j.nano.2015.10.011

36. Willemen HL, Huo XJ, Mao-Ying QL, Zijlstra J, Heijnen CJ, Kavelaars A. microRNA-124 as a novel treatment for persistent hyperalgesia. J Neuroinflammation (2012) 9:143. doi:10.1186/1742-2094-9-143

37. Brennan GP, Dey D, Chen Y, Patterson KP, Magnetta EJ, Hall AM, et al. Dual and opposing roles of microRNA-124 in epilepsy are mediated through inflammatory and NRSF-dependent gene networks. Cell Rep (2016) 14(10):2402-12. doi:10.1016/j.celrep.2016.02.042

38. Koukos G, Polytarchou C, Kaplan JL, Morley-Fletcher A, Gras-Miralles B, Kokkotou E, et al. microRNA-124 regulates STAT3 expression and is down-regulated in colon tissues of pediatric patients with ulcerative colitis. Gastroenterology (2013) 145(4):842.e-52.e. doi:10.1053/j.gastro.2013.07.001

39. Guo Z, Wu R, Gong J, Zhu W, Li Y, Wang Z, et al. Altered microRNA expression in inflamed and non-inflamed terminal ileal mucosa of adult patients with active Crohn's disease. J Gastroenterol Hepatol (2015) 30(1):109-16. doi:10.1111/jgh.12644

40. Zhao Y, Ma T, Chen W, Chen Y, Li M, Ren L, et al. microRNA-124 promotes the intestinal inflammation by targeting AHR in Crohn's disease. J Crohns Colitis (2016) 10(6):703-12. doi:10.1093/ecco-jcc/jjw010

41. Lakatos PL, Szamosi T, Lakatos L. Smoking in inflammatory bowel diseases: good, bad or ugly? World J Gastroenterol (2007) 13(46):6134-9. doi:10.3748/ wjg.v13.i46.6134

42. Zhou Q, Long L, Shi G, Zhang J, Wu T, Zhou B. Research of the methylation status of miR-124a gene promoter among rheumatoid arthritis patients. Clin Dev Immunol (2013) 2013:524204. doi:10.1155/2013/524204 
43. Nakamachi Y, Kawano S, Takenokuchi M, Nishimura K, Sakai Y, Chin T, et al. microRNA-124a is a key regulator of proliferation and monocyte chemoattractant protein 1 secretion in fibroblast-like synoviocytes from patients with rheumatoid arthritis. Arthritis Rheum (2009) 60(5):1294-304. doi:10.1002/ art. 24475

44. Nakamachi Y, Ohnuma K, Uto K, Noguchi Y, Saegusa J, Kawano S. microRNA-124 inhibits the progression of adjuvant-induced arthritis in rats. Ann Rheum Dis (2015) 75(3):601-8. doi:10.1136/annrheumdis-2014206417

45. Xia Y, Chen K, Zhang MH, Wang LC, Ma CY, Lin YL, et al. microRNA-124 involves in ankylosing spondylitis by targeting ANTXR2. Mod Rheumatol (2015) 25(5):784-9. doi:10.3109/14397595.2015.1023887

46. Bellon M, Lu L, Nicot C. Constitutive activation of Pim 1 kinase is a therapeutic target for adult T-cell leukemia. Blood (2016) 127(20):2439-50. doi:10.1182/ blood-2015-11-685032

47. Jeong D, Kim J, Nam J, Sun H, Lee YH, Lee TJ, et al. microRNA-124 links p53 to the NF-кB pathway in B-cell lymphomas. Leukemia (2015) 29(9):1868-74. doi:10.1038/leu.2015.101

48. Kim J, Jeong D, Nam J, Aung TN, Gim JA, Park KU, et al. microRNA-124 regulates glucocorticoid sensitivity by targeting phosphodiesterase $4 \mathrm{~B}$ in diffuse large B cell lymphoma. Gene (2015) 558(1):173-80. doi:10.1016/j. gene.2015.01.001

49. Hatziapostolou M, Polytarchou C, Aggelidou E, Drakaki A, Poultsides GA, Jaeger SA, et al. An HNF4 $\alpha$-miRNA inflammatory feedback circuit regulates hepatocellular oncogenesis. Cell (2011) 147(6):1233-47. doi:10.1016/j. cell.2011.10.043

50. Ning BF, Ding J, Liu J, Yin C, Xu WP, Cong WM, et al. Hepatocyte nuclear factor $4 \alpha$-nuclear factor- $\kappa \mathrm{B}$ feedback circuit modulates liver cancer progression. Hepatology (2014) 60(5):1607-19. doi:10.1002/hep.27177

51. Sun Y, Ai X, Shen S, Lu S. NF-кB-mediated miR-124 suppresses metastasis of non-small-cell lung cancer by targeting MYO10. Oncotarget (2015) 6(10):8244-54. doi:10.18632/oncotarget.3135

52. Ueda Y, Ando T, Nanjo S, Ushijima T, Sugiyama T. DNA methylation of microRNA-124a is a potential risk marker of colitis-associated cancer in patients with ulcerative colitis. Dig Dis Sci (2014) 59(10):2444-51. doi:10.1007/ s10620-014-3193-4

53. De Vuyst H, Franceschi S, Plummer M, Mugo NR, Sakr SR, Meijer CJ, et al. Methylation levels of CADM1, MAL, and miR124-2 in cervical scrapes for triage of HIV-infected, high-risk HPV-positive women in Kenya. J Acquir Immune Defic Syndr (2015) 70(3):311-8. doi:10.1097/QAI.0000000000000744
54. Farberov L, Herzig E, Modai S, Isakov O, Hizi A, Shomron N. microRNAmediated regulation of $\mathrm{p} 21$ and TASK1 cellular restriction factors enhances HIV-1 infection. J Cell Sci (2015) 128(8):1607-16. doi:10.1242/jcs.167817

55. Huang L, Ma J, Sun Y, Lv Y, Lin W, Liu M, et al. Altered splenic miRNA expression profile in H1N1 swine influenza. Arch Virol (2015) 160(4):979-85. doi:10.1007/s00705-015-2351-0

56. Bian L, Wang Y, Liu Q, Xia J, Long JE. Prediction of signaling pathways involved in enterovirus 71 infection by algorithm analysis based on miRNA profiles and their target genes. Arch Virol (2015) 160(1):173-82. doi:10.1007/ s00705-014-2249-2

57. Fu M, Gao Y, Zhou Q, Zhang Q, Peng Y, Tian K, et al. Human cytomegalovirus latent infection alters the expression of cellular and viral microRNA. Gene (2014) 536(2):272-8. doi:10.1016/j.gene.2013.12.012

58. Yen LC, Lin YL, Sung HH, Liao JT, Tsao CH, Su CM, et al. Neurovirulent flavivirus can be attenuated in mice by incorporation of neuron-specific microRNA recognition elements into viral genome. Vaccine (2013) 31(49):5915-22. doi:10.1016/j.vaccine.2011.09.102

59. Patel M, Verma A, Aslam I, Pringle H, Singh B. Novel plasma microRNA biomarkers for the identification of colitis-associated carcinoma. Lancet (2015) 385(Suppl 1):S78. doi:10.1016/S0140-6736(15)60393-2

60. Joglekar MV, Januszewski AS, Jenkins AJ, Hardikar AA. Circulating microRNA biomarkers of diabetic retinopathy. Diabetes (2016) 65(1):22-4. doi:10.2337/ dbi15-0028

61. de Candia P, Torri A, Pagani M, Abrignani S. Serum microRNAs as biomarkers of human lymphocyte activation in health and disease. Front Immunol (2014) 5:43. doi:10.3389/fimmu.2014.00043

62. Roy-Chaudhuri B, Valdmanis PN, Zhang Y, Wang Q, Luo QJ, Kay MA. Regulation of microRNA-mediated gene silencing by microRNA precursors. Nat Struct Mol Biol (2014) 21(9):825-32. doi:10.1038/nsmb.2862

Conflict of Interest Statement: The authors declare that the research was conducted in the absence of any commercial or financial relationships that could be construed as a potential conflict of interest.

Copyright (C) 2016 Qin, Wang, Su and Liu. This is an open-access article distributed under the terms of the Creative Commons Attribution License (CC BY). The use, distribution or reproduction in other forums is permitted, provided the original author(s) or licensor are credited and that the original publication in this journal is cited, in accordance with accepted academic practice. No use, distribution or reproduction is permitted which does not comply with these terms. 